\title{
Activismo antitrumpista: Ken Burns y Michael Moore en la trinchera del documental estadounidense
}

\author{
Activism against Donald Trump: Ken Burns and \\ Michael Moore in the trench of the \\ American documentary
}

\author{
Liliana Cordero Marines (iD) http://orcid.org/0000-0001-6381-5010 \\ Universidad Nacional Autónoma de México,México, lilianacorde@gmail.com
}

Recepción:

$03 / 02 / 2020$

Aprobación:

$11 / 06 / 2020$

\begin{abstract}
Understanding the documentary as a tool that acquires an active role in the construction of political identities, shaping the history of communities, the goal is to analyze documentaries of two American filmmakers -Michael Moore and Ken Burns- and the relation Donald Trump's candidacy and presidential management. By means of a qualitative interpretive methodology, it is discovered that the directors and their respective documentaries-Michael Moore in Trumpland (2016), Fahrenheit 11/9 (2018) and The Central Park Five (2012)-, participate in the current national debate. Concurring in a context they find dangerous and urgent, despite their profound differences and stark contrasts. It is concluded that in the United States, for nine decades, the documentary remains a necessary tool for dissent, opening discussions on issues that are considered of national relevance.
\end{abstract}

Key words: documentary, political reshape, Donald Trump, dissent, national debate.

Resumen: Al entender al documental como una herramienta que adquiere un papel activo en la construcción de identidades políticas y en la conformación de la historia de las comunidades, el objetivo del texto es analizar los documentales de dos cineastas estadounidenses -Michael Moore y Ken Burns- en relación con la candidatura y gestión presidencial de Donald Trump. A través de una metodología cualitativa de corte interpretativo, se descubre que los directores y sus respectivos documentales - Michael Moore in Trumpland (2016), Fabrenheit 11/9 (2018) y The Central Park Five (2012) - abonan y participan en el debate nacional actual, coincidiendo en un contexto que consideran peligroso y urgente, a pesar de sus profundas diferencias y matices. Se concluye que en Estados Unidos, como desde hace nueve décadas, el documental sigue siendo una herramienta necesaria de la disidencia para abrir discusiones sobre temas que se consideran de relevancia nacional.

Palabras clave: documental, reconfiguración política, Donald Trump, disenso, debate nacional. 


\section{Introducción}

El propósito central de este texto es analizar los documentales Michael Moore in Trumpland (2016), Fabrenheit 11/9 (2018) de Michael Moore y The Central Park Five (2012) de Ken Burns, en el marco de la oposición política a Donald Trump en tanto candidato y presidente de Estados Unidos. En primera instancia se considera relevante analizar la producción de documentales como una herramienta útil en contextos coyunturales y de debate político. En segundo lugar, como una forma de expresión que adquiere un papel activo en la construcción de identidades políticas, así como en la conformación de la historia de las comunidades. En tercero, se espera contribuir al análisis de América del Norte vista desde el documental.

El empresario Donald J. Trump ganó las elecciones a la presidencia de Estados Unidos en noviembre de 2016, ante la sorpresa del partido demócrata, la prensa nacional e internacional, la academia especialista en ciencia política y un conjunto de personajes provenientes de distintos ámbitos, quienes afirmaron con certeza la imposibilidad de tal triunfo. Los resultados electorales impactaron de manera inmediata en la política interna, la política internacional, las relaciones económicas tanto en Norteamérica como en el resto del mundo, pero también en diversos ámbitos de la cultura y la sociedad estadounidense.

Rápidamente tuvieron lugar manifestaciones de descontento entre diversos sectores estadounidenses. Una de las más grandes e inmediatas expresiones, Women's March, tuvo lugar en Washington D. C., un día después de la investidura de Donald Trump. Pero hoy en día se han movilizado estudiantes y activistas en la mayoría de las ciudades grandes de Estados Unidos al grito de "Not my president", con el fin de expresar tanto su descontento como su apoyo a las minorías que han sido atacadas por esta figura presidencial. Expresiones como Occupy Movement o Black Lives Matter se han sumado a la causa. Sin embargo, también ha habido muestras de descontento y activismo desde otras trincheras, una de ellas es la producción de cine documental.

El documental es un género cinematográfico con una larga y diversa trayectoria. Se le ha considerado (Dittus, 2012) como una práctica discursiva que pretende hacer afirmaciones directas del mundo; que propone modelos de la realidad desde la particular visión del realizador, al tiempo que busca una relación verosímil con el entorno. Desde las primeras expresiones de hace más de un siglo hasta la producción contemporánea, se puede trazar un continuo por la presencia de una intención transformadora (Sierra y Montero, 
2015: 11-20). ${ }^{1}$ Esta característica, relevante para el tema que nos ocupa, se le ha atribuido fundamentalmente al documental político. Es considerado como tal (Dittus, 2012: 40) cuando se posiciona frente a una disputa de poder donde se definen maneras de organizar la sociedad, de construir la identidad, de proyectar los estados nacionales, etc. Y en ese posicionamiento busca propiciar apoyo, responsabilidad, congregación o incluso distanciamiento. Mediante estos denominadores, con combinaciones y matices particulares definidos por distintos contextos y motivaciones, una buena parte de la producción de documentales ha construido posturas críticas en relación con los distintos grupos hegemónicos a lo largo del tiempo. En Estados Unidos, la producción de este cine es particularmente emblemática, pues ha construido una genealogía de casi nueve décadas.

$\mathrm{Al}$ partir de que hay una relación entre el quehacer documental y el contexto donde se produce (Ferro, 2008), se consideró relevante analizar los documentales Michael Moore in Trumpland (2016), Fabrenheit 11/9 (2018) y The Central Park Five (2012). Los dos primeros con una importante actividad en los recientes contextos electorales de Estados Unidos, mientras que el tercero ha sido activado en los últimos meses para advertir sobre el racismo hacia la comunidad afrodescendiente por parte de Donald Trump. Aunque los directores de los documentales no comparten las mismas posturas políticas y tienen estilos creativos radicalmente distintos, sí confluyen en el cuestionamiento a la política y las posturas del presidente de Estados Unidos. Estos ejemplos resultan pertinentes, porque dan cuenta de la relación entre un momento de tensión política y el uso de documentales como una herramienta para incidir en el entorno.

\section{Los caminos andados en el análisis del documental estadounidense}

La dimensión política del documental estadounidense ha propiciado un amplio conjunto de investigaciones. Para los fines de este texto, hay dos enfoques que conviene poner de relieve. Uno se ocupa de explorar las posibilidades de los discursos audiovisuales para incidir en el ámbito de lo público y en la construcción de la comunidad (Geiger, 2011). El otro concluye que en Estados Unidos el documental se ha convertido en un lugar para discutir la política social, desde la lucha por la libertad y los derechos civiles, hasta el papel del gobierno (Kahana, 2008). Ambos son importantes por el tipo de

1 Esto no significa que la totalidad de la producción documental comparta el espíritu transformador, pero sí que éste ha estado presente en las diferentes etapas y momentos históricos. 
relación que los documentalistas y sus producciones establecen con un contexto determinado.

Tanto el trabajo de Michel Moore como el de Ken Burns han suscitado numerosas reflexiones. Respecto al primero, se ha analizado la eficacia (Dittus, 2012) de Fahrenheit 9/11 (2004), la comedia como función retórica en ese mismo documental (Fleischmann, 2007), los distintos aspectos del dispositivo retórico que establece en sus documentales (Benson y Snee, 2015), la paradoja de su éxito y amplio consumo (Granados, 2006). Hay, por ejemplo, análisis de la representación que hace de la frontera Canadá-Estados Unidos (Martínez-Zalce, 2005). Incluso, se le ha cuestionado la relación que establece con la verdad y la incidencia práctica que tiene en el ámbito de lo político (Ricciardelli, 2014).

Respecto a Ken Burns se pueden hallar trabajos que se centran en sus influencias como autor y los aspectos que han garantizado su éxito televisivo (Edgerton, 2001). Las revisiones críticas analizan la multipremiada serie de su autoría The Civil War (1990). Se le señala no haber incorporado los roles de las minorías, las mujeres y la comunidad afrodescendiente (Brent Toplin, 1996). Textos más recientes lo caracterizan como un documentalista que tiende a generar consenso en el retrato de la cultura y la historia estadounidense, pero que en tal ejercicio suprime la diversidad cultural (Ricciardelli, 2014). Aunque el último señalamiento resulta cuestionable, su importancia radica en que brinda una oportunidad para construir nuevas reflexiones, derivadas de la contraposición de los hallazgos arrojados por el análisis de The Central Park Five (2012).

La gestión del presidente Donald Trump se ha analizado desde la política arancelaria (Lovely y Liang, 2018), hasta la percepción que de Estados Unidos -bajo su mandato- se tiene a nivel internacional (Dixon y Skidmore, 2018). Con base en entrevistas a fuentes cercanas se ha hablado del caos y la incompetencia que reina en la Casa Blanca, de los hábitos que tiene en relación con Fox News y Twitter, la opinión que sobre él tienen sus allegados y de la incredulidad al alcanzar la presidencia (Wolff, 2018). Otros más reúnen un conjunto de ensayos que examinan la gestión de Trump desde tres grandes perspectivas: lo político, lo económico y lo cultural (Núñez, 2018). Para el presente texto resulta particularmente relevante el análisis de la representación crítica que se hace de él en uno de los capítulos de Los Simpson, mostrándolo como una persona iletrada, despótica, sin ética, vanidosa y vacía, porque refleja las acciones desde otras trincheras y su intento por confrontar a la sociedad estadounidense (Martínez-Zalce, 2018). 
Si bien la tradición de documental estadounidense tiene casi noventa años, es posible afirmar que a pesar de la gran cantidad de investigaciones que se han desarrollado (MacDonald, 2013; Geiger, 2011; Kahana, 2008; Leuthold, 2001; Lerner, 1992; Bleum, 1971) queda mucho por hacer. Hace falta indagar las coincidencias o distanciamientos entre documentalistas que tienen lugar en la arena política. Sobre todo, aún se requiere identificar las características del papel activo que los distintos estilos y posturas en el mundo del documental adquieren en el debate nacional. Por ello es necesario discernir en qué consisten estas expresiones y su importancia en el contexto de la crisis política que enfrenta Estados Unidos hoy en día.

\section{Anclando las miradas de Michael Moore y Ken Burns}

A pesar de no ser cineasta de formación, Michael Moore ha dirigido un buen número de documentales ${ }^{2}$ y ha acumulado un conjunto importante de galardones ${ }^{3}$ que se han traducido en un vasto y robusto reconocimiento internacional. En el mundo de la cinematografía se le atribuye haber demostrado el enorme potencial del género documental en términos de recaudación económica y de entretenimiento (Plantinga, 2014: 9).

La mayor parte de las reflexiones que ha generado su trabajo reconoce los alcances e influencia de su obra. Sin embargo, las críticas a sus películas, a sus posturas políticas y a su persona no son pocas. Ricciardelli (2014: 106-124), por ejemplo, le critica haber acumulado una fortuna haciendo documentales que se oponen al modelo económico capitalista, lo cual se interpreta como una contradicción. Entre otras cosas porque Michael Moore se identifica en ellos con la clase trabajadora. Incluso, duda y cuestiona la veracidad de sus argumentos. Tampoco parece gustarle cuando ha puesto sus fuentes al alcance del público, señalándole una compulsión por validar sus documentales. Le reprocha elaborar representaciones de la alteridad sin darle voz. Asimismo, plantea que usa sus documentales para beneficiarse como líder político.

2 Roger \& Me (1989), Pets or Meat: The Return to Flint (1992), Canadian Bacon (1995), The Big One (1997), Bowling for Columbine (2002), Fabrenheit 9/11 (2004), Sicko (2007), Slacker Uprising (2008), Capitalismo: Una historia de amor (2009), ¿Qué invadimos ahora? (2015), Michael Moore in Trumpland (2016), Fabrenheit 11/9 (2018).

3 En 2002 ganó el premio Oscar y el premio César por Bowling for Columbine (2002); en 2004 obtuvo la Palma de Oro del Festival de Cannes por Fahrenheit 9/11 (2004); en 2007 estuvo nominado al Oscar nuevamente por Sicko (2007). Ha ganado el premio de la Crítica Cinematográfica al Mejor Largometraje en 2002 por Bowling for Columbine (2002), en 2004 por Fabrenheit 9/11 (2004) y en 2007 por Sicko (2007), entre otras distinciones. 
Pero también es innegable que sus películas han molestado a mucha gente (Plantinga, 2014; Nichols, 2013; Oberacker, 2009). Éstas se han caracterizado principalmente por criticar a los gobiernos de Estados Unidos y sus políticas neoliberales. A pesar de ello, sus películas tienen alcance mundial, porque las distribuidoras consideran que a largo plazo es más rentable difundir su trabajo que censurarlo (Kahana, 2008). ${ }^{4}$

Sin embargo, sus documentales tienden a convertirse en temas de discusión que se suman activamente al debate político estadounidense (Kahana, 2008). Se echa mano de ellos para expresar el descontento con las élites políticas y sus decisiones. También es cierto que con enorme eficacia se posiciona siempre como ciudadano de Flint, Michigan. Bajo estas coordenadas no sólo ancla su compromiso con una comunidad golpeada por una economía en declive, sino que nos dice cuál es su identidad y desde dónde ve el mundo. Debe recordarse que no sólo dirige sus documentales, sino que es personaje de ellos (Plantinga, 2014; Oberacker, 2009; Nichols, 2013), ya sea como entrevistador o montando situaciones donde pone en aprietos a sus adversarios (Kahana, 2008; Oberacker, 2009).

En la política contemporánea estadounidense se le ha reconocido por haber sido de los pocos en advertir sobre las posibilidades de que Donald Trump llegara a la presidencia de Estados Unidos en las elecciones de 2016 (Wulfsohn, 2020). Los títulos que se revisarán son Michael Moore in Trumpland (2017) y Fabrenheit 11/9 (2018), cuya intención fue -en ambos casos- incidir en el electorado que votaría a favor de Donald Trump en 2016 y 2018, respectivamente.

Por su parte, Ken Burns es hijo de un profesor universitario y estudió una licenciatura en Diseño y Estudios Cinematográficos. Después de graduarse fundó la productora Florentine Films e inició su trayectoria como creador de documentales de historia y cultura estadounidense. La mayoría de sus trabajos

4 Eso no significa que su trabajo no haya tenido intentos de censura. De hecho, ha habido momentos en los que su propia seguridad ha corrido peligro y ha tenido que ser cuidado por agentes de seguridad debido a sus posturas y declaraciones. Por ejemplo, en 2003, después de su discurso en relación con la Guerra de Irak, al recibir el premio Oscar al Mejor documental, dijo: "He invitado a mis compañeros nominados a subir al escenario con nosotros. Están aquí en solidaridad conmigo porque nos gusta la no ficción, aunque vivimos en tiempos ficticios. Vivimos en un momento en que tenemos resultados electorales ficticios que eligen a un presidente ficticio. Vivimos en un momento en que tenemos a un hombre que nos envía a la guerra por razones ficticias. Se trate de la ficción de la cinta aislante o de la ficción de las alertas naranjas: estamos contra esta guerra, señor Bush. ¡Qué vergüenza, señor Bush! ¿Qué vergüenza! Y muy pronto tendrá al Papa y a las Dixie Chicks contra usted, ;su tiempo se acaba! Muchas gracias" (Moore, 2013: 19). 
ha sido producida y distribuida por el Public Broadcasting Service (PBS). Su primer éxito se le atribuye a la serie documental The Civil War (1990), que se presentó en la televisión estadounidense en horario central. La gran acogida entre el público superó cualquier cálculo (Edgerton, 2001). Se sustentó exclusivamente en fotografías fijas que había ido acumulando a lo largo de varios años de investigación -en archivos públicos y privados- y las nutrió con relatos, testimonios, discursos, noticias, memorias, etc., de la época (Ricciardelli, 2014: 80-81). Esta estrategia de construcción audiovisual, junto con el trabajo de investigación que sustenta las respectivas historias, se han convertido en su sello característico.

Hoy en día tiene alrededor de 29 documentales o series documentales acerca de la historia y la cultura de Estados Unidos. ${ }^{5}$ Ha sido ampliamente reconocido. Ha ganado en tres ocasiones el premio Emmy, pero lo han nominado en quince emisiones. Aunque en la mayor parte de su carrera ha mantenido su posición política al margen de la actividad profesional (Collins, 2016), tanto su trabajo como algunas declaraciones revelan ciertas características de ésta. En entrevista ha sostenido que la Historia es una herramienta fundamental para tener perspectiva y proceder mediante un pensamiento racional (Stern, 2017). Su principal crítica a los medios en la actualidad es que carecen de un punto de vista histórico, lo cual provoca confusión y poca claridad en los hechos que informan (Stern, 2017). Una preocupación recurrente en sus documentales es el tema de la histórica y persistente discriminación racial hacia la comunidad afrodescendiente en Estados Unidos. En relación con este tema ha señalado que las tensiones raciales en el país son profundas. Considera que la idea de que Estados Unidos vive una época posracial por haber tenido a un presidente afrodescendiente es equívoca (Stern, 2017).

En la teoría del documental se le ha caracterizado como un realizador conservador (Nichols, 2013). Sin embargo, cuando se abrió la posibilidad de que Donald Trump llegara a la presidencia, Ken Burns consideró que era hora de tener una posición explícita y activa políticamente (Collins, 2016). Ha declarado que Trump representa una amenaza en muchos sentidos (Stern, 5 Brooklyn Bridge (1981), The Shakers (1984), The Statue Liberty (1985), Huey Long (1985), Thomas Hart Benton (1988), The Congress (1989), The Civil War (1990), Empire of the Air (1991), Baseball (1994), The West (1996), Thomas Jefferson (1997), Lewis \& Clark (1997), Frank Lloyd Wright (1988), The Story of Elizabeth Cady Stanton and Susan B. Anthony (1999), Jazz (2001), Mark Twain (2002), Horatio's Drive (2003), Unforgivable Blackness (2005), The National Parks (2009), Baseball, The Tenth Inning (2010), Probibition (2011), The Dust Bowl (2012), The Central Park Five (2013), The Address (2014), The Roosevelts (2014), Jackie Robinson (2016), The Vietnam War (2017), The Mayo Clinic (2018), Country Music (2019). 
2017), no sólo porque pone en juego la democracia, sino porque se corre el peligro de que afloren males históricos como la intolerancia racial. Burns opina también que el papel que este personaje ha adquirido en la política estadounidense refleja un retroceso que denigra la historia del país (Ferner, 2016). Para él resulta inadmisible que insulte a los veteranos, denigre a las mujeres, a los inmigrantes y a los musulmanes (Ferner, 2016). Simplemente, desde su perspectiva, no es alguien calificado para ser presidente (Collins, 2016).

En el documental The Central Park Five (2012), Burns cuenta la historia de los cinco jóvenes afrodescendientes que por motivos raciales fueron acusados sin pruebas de golpear y atacar sexualmente a una mujer blanca en 1989, en Nueva York. Destaca en los hechos que el entonces empresario adquirió un papel activo en el linchamiento mediático y social de estos jóvenes. Y aunque es un documental que no se pensó con fines electorales, desde 2016 ha sido usado tanto por el director como por otros medios como herramienta para poner en evidencia la postura racial de Trump.

Como puede observarse, uno y otro caso presentan características radicalmente distintas. Si bien ambos realizadores gozan de amplio reconocimiento, el de Moore está sobre todo en los festivales y salas de cine; mientras que el de Burns radica en el ámbito de la televisión pública. El primero se hizo cineasta por una motivación política relativa a una problemática económica que estaba enfrentando la comunidad donde creció, y el segundo por un interés meramente académico. De ahí que en el ámbito de lo político sus maneras de proceder también difieran. Moore combina explícitamente su profesión con su postura política. Burns, por el contrario, intenta mantener un vínculo sobrio entre tales ámbitos. El primero pretende incidir en el debate público de la política contemporánea. El segundo en la memoria colectiva, a través de la construcción de la historia y la cultura estadounidense.

Lo interesante está en que se seleccionaron materiales fílmicos que aunque difieren de forma radical en motivación, estilo y temporalidad, confluyen en un mismo momento espacio-temporal como herramientas mediáticas para concientizar al público acerca de los peligros que entraña para la población, la historia y la cultura de Estados Unidos un mismo personaje: Donald Trump, el actual presidente de ese país.

\section{Estrategia para entender el documental estadounidense en la era Trump}

Para entender el papel que estos documentales están jugando en el debate político contemporáneo en Estados Unidos en torno a Donald Trump, es 
necesario establecer un conjunto de planteamientos generales. El primero se refiere a la relación ineludible entre el documental y el mundo histórico (Nichols, 1997; Ferro, 1980). Además de retratar y acercarnos acontecimientos específicos -en nuestro caso las tensiones del contexto electoral estadounidense de 2016 y los subsecuentes cuestionamientos a las posturas y acciones del magnate estadounidense-, los documentales reflejan la mirada, inquietudes y preocupaciones que tuvieron lugar en determinadas coordenadas espaciotemporales. Es decir, las reacciones y/o motivaciones de Moore, Burns y las comunidades a las que pertenecen.

El segundo planteamiento pone de relieve el diálogo que se establece entre el realizador y el público (Nichols, 1997) acerca de uno o varios temas que les atañen a ambos, como las capacidades, cualidades y desempeño del Ejecutivo estadounidense. Tal interlocución suele construirse mediante un acuerdo implícito. El director se compromete a exponer información de manera ética y fiable, mientras que el público dará credibilidad a los hechos y argumentos narrados, debido a la legitimidad profesional que ostenta cada realizador y su trayectoria (Plantinga, 2014). Este dispositivo tiende a adquirir particular importancia en lugares como Estados Unidos, donde históricamente ha habido un fuerte control de los medios de comunicación y de la información que se difunde por parte de los grupos hegemónicos.

El tercero se sustenta en el trabajo de Jonathan Kahana (2008), quien sugiere que en Estados Unidos el documental se ha convertido en una forma de cultura política. Partiendo de que tiene un potencial crítico que es inseparable de su función analítica, señala que es al mismo tiempo una forma de democracia y de pedagogía social. Mediante la investigación y la argumentación, estas películas ponen bajo los reflectores aspectos y sucesos que construyen la historia y la vida pública estadounidense. Kahana (2008) afirma que en Estados Unidos aspectos como la lucha por los derechos civiles, el desempeño del gobierno y el poder de los medios masivos de comunicación, se discuten y toman lugar en el cine documental, abriendo y nutriendo una suerte de debate nacional. Esto sucede porque el dispositivo audiovisual recoge evidencia de la experiencia y la entrega a la esfera pública, donde le presta fuerza política a los movimientos sociales y alimenta con datos y representaciones gráficas el imaginario social (Kahana, 2008).

Para Kahana (2008), el uso del documental por parte de activistas, intelectuales, miembros de las organizaciones sociales, agencias del gobierno o grupos comunitarios permite una reconfiguración del discurso político. Pero también debilita las oposiciones tradicionales entre el discurso popular y oficial, entre la idea de arte y cultura de masas, lo mismo que entre el 
conocimiento académico y el sentido común. Funciona como un articulador del imaginario social y sus múltiples niveles. Esta postura es importante porque ayuda a situar el diálogo entre el realizador y el público en el terreno de lo político. Asimismo, contempla el vínculo entre diversos actores sociales y el documental, como parte del impacto e incidencia que alcanza en la reconfiguración social. Esto nos invita a poner atención en el modo en que los documentales y realizadores que conforman el corpus se han relacionado con el entorno.

Finalmente, es necesario contextualizar cada uno de estos documentales y realizadores en la larga genealogía de la producción documental estadounidense. Al seguir la revisión que hace Barnouw (2011) en relación con el documental político en este país, se puede decir que su trayectoria consta de nueve décadas. De manera nada casual inicia con la crisis económica de 1929, en reacción a los efectos de la Gran Depresión y a un contexto de fuerte control informativo. En la ciudad de Nueva York surge la Liga de Trabajadores Cinematográficos y Fotográficos que se da a la tarea de retratar sucesos como cierres de establecimientos, asentamientos irregulares a causa de la pobreza, huelgas, etcétera, que después difundían en proyecciones abiertas al público.

Con este antecedente, ya avanzada la década de 1930, se forma también la cooperativa Frontier Films, que se abocó a hacer documentales de corte político intentando retratar de manera realista las problemáticas que se enfrentaban en Estados Unidos -racismo, pobreza, desocupación laboral-y en otras latitudes del globo. ${ }^{6}$ En la década de 1950, con todo y la persecución anticomunista encabezada por el senador Joseph McCarthy, también se produjeron algunos documentales que intentaron registrar los conflictos laborales. ${ }^{7}$ En las siguientes dos décadas tuvo lugar una enorme preocupación entre los documentalistas por construir miradas de la guerra de Vietnam distintas a las oficiales. ${ }^{8}$ En los años ochenta los documentalistas pusieron los reflectores en los conflictos armados en Centroamérica y Sudamérica. ${ }^{9}$

6 Por ejemplo, la cooperativa neoyorquina Frontier Films se ocupó de la Guerra Civil Española con Heart of Spain (1937) y del conflicto entre Japón y China con China Strikes Back (1937).

7 Como el producido por la comunidad chicana: Salt of The Earth (1953), de Jacobo Biberman, que fue prohibido en Estados Unidos.

8 Por ejemplo: Vietnam in the year of the pig (1968) de Emile Antonio, Hearts and Minds (1974) de Peter Davis y Winter Soldiers (1971) de autoría anónima.

9 Por ejemplo: El Salvador: Another Vietnam (1981) de Glen Silver y T. T. Vasconcellos, From the Ashes: Nicaragua Today (1981) de Hellen Sollberg, Cuando las montañas tiemblan (1983) de Pamela Yates, Tom Sigel y Peter Kinoy. 
Este contexto es el que precede al trabajo de Michael Moore. Al final de la década de 1980 se estrenó su primer documental Roger and Me (1989), el cual llegó a las salas con bajas expectativas, pues hace una fuerte crítica a la empresa General Motors por los daños económicos que causó en Flint, Michigan, al cerrar una de sus plantas ensambladoras de autos; pero sorprendió enormemente por el éxito que tuvo entre el público. En su momento, incluso, se le calificó como el documental que más dinero había recaudado.

La década de 1980 fue muy fructífera en el terreno del documental estadounidense. En ese mismo periodo surgió el documental de corte histórico, quizás con menos aspiraciones políticas de incidir en lo inmediato, pero sí con el claro objetivo de abonar a la historia y la cultura estadounidense. Por las características del trabajo de Ken Burns conviene enfatizar que este tipo de películas se comenzaron a hacer echando mano de materiales fílmicos que habían sido producidos por el gobierno varios años atrás. Con el paso del tiempo fueron perdiendo importancia para los regímenes políticos y se convirtieron en materiales accesibles. Además, su uso no generaba ningún costo, por lo tanto se facilitaba su producción.

Dentro de este tipo de documental, Barnouw (2011: 283-287) ubica un conjunto de vertientes que atribuye al documental estadounidense. Cada una con distinta estrategia narrativa. Las primeras eran una suerte de compilaciones de materiales fílmicos, cuyo hilo conductor era la voz de un solo narrador, el cual desempeñaba un papel omnisciente. Las posteriores mezclaban tomas históricas con relatos contemporáneos de personas que fueron parte de los sucesos. Otro camino más fue la biografía fílmica. Con uno y otro estilo, este tipo de trabajos documentaron diversas luchas sociales y pasajes de la historia de Estados Unidos -el papel de las mujeres en los conflictos sindicales ${ }^{10} \mathrm{o}$ en la industria de armamento ${ }^{11}$ y el reconocimiento de la dignidad de la población afrodescendiente-.$^{12}$

La última vertiente del documental histórico se refiere explícitamente a The Civil War (1990) de Ken Burns, a quien Barnouw (2011: 292) considera paradigmático en este subgénero. Se refiere a documentales hechos sobre todo para la televisión, muchos de ellos en varios capítulos que están sustentados en un serio trabajo de investigación, nutrido con diversas fuentes testimoniales y de archivo. El sonido y la música tienen un papel

10 Union Maids (1976) de Julia Reichert, James Klein y Miles Mogulescu, y With Babies and Banners (1977) de Larraine Gray, Lynn Goldfar y Anne Bohlen.

11 The Life and Times of Rosie the Riveter (1980) de Connie Field.

12 Men of Bronze (1977) de William Milles y Miles of Smiles (1983) de Jack Santino y Paul Wagner. 
preponderante en la narración. Hay además un ejercicio de incluir distintas versiones sobre los sucesos que se están narrando. Desde entonces, Burns ha transitado un largo camino nutriendo no sólo la historia y la cultura estadounidense, sino también abonando a la producción de documentales.

Para cerrar este apartado, es importante señalar que tanto los planteamientos enunciados como la breve contextualización histórica son fundamentales en la interpretación del corpus. Con base en los primeros se implementó una metodología cualitativa de corte interpretativo, que permitió contextualizar a los directores y sus películas en el escenario trumpista, así como analizar el contenido de cada una de ellas (Giroux y Tremblay, 2011). Este enfoque pone énfasis tanto en los elementos que conforman las piezas del corpus como en las personas que suscriben las películas. Las coordenadas revisadas de la genealogía del documental estadounidense, por su parte, muestran que los planteamientos de Kahana (2008) tienen sustento y validez tanto en la actualidad como en décadas precedentes. Es decir, independientemente de los estilos de uno u otro realizador, los documentales constituyen una forma de cultura política que tiene trayectoria histórica.

\section{Michel Moore y su crítica a Donald Trump}

\section{Michael Moore in Trumpland (2016)}

El activismo de Michael Moore en contra de Donald Trump comenzó en 2016, unas semanas antes de que tuvieran lugar las elecciones presidenciales en Estados Unidos. Preocupado por lo que veía como el inminente triunfo del candidato, decidió intervenir. Montó un número para mostrar al público de ciudades conservadoras los aspectos negativos de votar por Trump y los muchos positivos que había en votar por la candidata demócrata Hillary Clinton. Poco tiempo después este ejercicio se convertiría en una película, que es el registro de una de las presentaciones en Wilmington, Ohio.

Vestido como siempre: sudadera, pantalón de mezclilla, tenis y una gorra del equipo de futbol americano de San Francisco, su estrategia general fue buscar puntos de encuentro con el público. La pericia consistió en identificar la diversidad de los asistentes y construir puentes afines con cada uno de ellos: republicanos, demócratas, mujeres, jóvenes, mexicanos, musulmanes, etc. Para ablandar los semblantes tensos del público republicano, comenzó a describir y alabar atributos que les suelen caracterizar, al tiempo que se burlaba de la molesta y relajada relatividad que propicia el juicio flexible de la 
gente demócrata. En relación con el público mexicano y musulmán, empezó pidiendo a sus ayudantes que pusieran un muro alrededor de los primeros, mientras solicitó que a los segundos un dron con una cámara les sobrevolara por la cabeza. "Sólo para mantenerlos vigilados", comentó Moore. Entre las risas nerviosas del público afirmó tranquilamente: "No se preocupen, está todo bien, es únicamente para que el resto de la gente se sienta cómoda”. La situación era efectiva porque cuestionaba la racionalidad de las medidas que enunciaba Trump.

Moore estableció una conexión con los jóvenes caracterizados como millenials, aceptando que las generaciones antecesoras les han arruinado el mundo. Afirmó que ellos no le preocupan porque no odian a la gente por el color de su piel ni por su preferencia sexual. Al señalar que el mundo ha sido gobernado por hombres y que todo ha salido mal, se acercó a las mujeres. Reconoció que la independencia que han alcanzado asusta mucho al mundo patriarcal. A ambos sectores intentó advertirles que habría un retroceso en los ámbitos mencionados si Trump llegaba a la presidencia. No omitió caracterizarlo como misógino, ni mencionar el hecho de haber tenido sirvientes toda su vida. Si bien aceptó que los demócratas han dejado de ser una opción, le imploró al público no usar el voto a favor de Trump como terapia de ira.

Independientemente de cuánta gente asistió a presenciar este monólogo, lo cierto es que Donald Trump ganó las elecciones y se convirtió en el presidente de Estados Unidos. Sólo unos cuantos alcanzaron a calcular su inminente triunfo. De manera sorprendente, muchas de las advertencias de Michael Moore -que hicieron reír al público por absurdas- ahora son parte de la cotidianidad.

En términos del lenguaje audiovisual, podemos decir que como la mayor parte de sus documentales (Nichols, 2013), en éste también es él un personaje principal y le habla al público desde su posición personal, desde su postura política y desde lo que considera es mejor para la población. Sin embargo, se distancia de la estrategia expositiva usada en el resto de sus trabajos. Aquí su persona tiene un peso considerablemente mayor. Salvo los minutos introductorios, todo el documental se desarrolla al interior de un auditorio, donde él y el diálogo que se establece con las reacciones faciales del público - provocadas por los comentarios de Moore-son los únicos personajes. Es decir, esta vez no hay material de archivo, no hay entrevistas, así como tampoco hay emboscadas, pues el público -aunque republicano y conservador- sabía que iba al teatro a sentarse un par horas a escuchar a Michael Moore.

En términos de las modalidades de documental que señala Nichols (2013), Michael Moore in Trumpland (2016) se erige fundamentalmente en 
la modalidad participativa. Esto se debe a que su estructura se construye con base en la interacción o diálogo que se establece entre el director y los sujetos del mundo histórico -el público que asiste al teatro a ver a Michael Moore-. Para Nichols (2013), el valor de dicha estrategia está en que las características de este encuentro muestran un fragmento concreto del mundo. En el caso que nos ocupa: los rostros tensos, graves, sonrojados, aliviados, nerviosos o sonrientes, se usan para mostrar qué es lo que pasa entre los votantes de la elección presidencial de 2016. Pero también el hecho de poder observar al director respondiendo e interactuando en las mismas coordenadas espaciotemporales que los sujetos, le da la oportunidad de actuar como "mentor, crítico, interrogador, colaborador o provocador” (Nichols, 2013: 211).

\section{Fabrenheit 11/9 (2018)}

El título alude a la fecha en que se realizó la elección primaria de Estados Unidos, en noviembre de 2018. La importancia de este ejercicio electoral estaba en que los resultados suelen dar la pauta de lo que sucederá en las siguientes elecciones presidenciales; en este caso las de 2020, es decir, si Donald Trump estará al frente de un segundo periodo o no. El objetivo fue dar herramientas a los electores para que ejercieran un voto crítico.

Moore hace una fuerte crítica a Donald Trump y muestra un conjunto de declaraciones del presidente de Estados Unidos; algunas son inteligibles, otras violentas, pero también las hay racistas y misóginas. Dichas declaraciones muestran cómo este personaje está constantemente descolocado: da órdenes a los medios y se pelea con ellos; los insultos o descalificaciones son comunes en cuanto debate establece; no ha dejado de estar en campaña y ha sugerido alargar el periodo presidencial; pidió la pena de muerte para cinco jóvenes afrodescendientes, acusados sin pruebas de golpear y asaltar sexualmente a una mujer blanca en Central Park; quiere construir un muro en la frontera con México, etcétera.

Con el objetivo de sacudir al espectador, Fahrenheit 11/9 reúne fotografías y declaraciones de Trump sobre su hija Ivanka. Las imágenes los muestran en situaciones, posiciones y acercamientos fuera de lugar para un padre y una hija. El documental señala que uno de sus principales problemas es que siempre ha cometido los crímenes a plena luz del día, sugiriendo que es incapaz de discernir entre lo correcto y lo incorrecto.

Sin embargo, responsabiliza a las presidencias demócratas de Bill Clinton y Barak Obama del triunfo de Trump, por alejarse de la población y volverse incapaces de identificar sus principales necesidades, ya que 
minimizaron movimientos como Occupy Wall Street. El sistema democrático tampoco se libra. Para Moore no hay una democracia real cuando en una elección no se otorga el cargo a quien obtuvo la mayor cantidad de votos; lo mismo pasa cuando la mitad de la población no puede votar.

Desencantado de todo, Moore decide poner los reflectores sobre Bernie Sanders y las candidaturas al Congreso, representadas por personas provenientes de minorías, mujeres de origen musulmán o latino, pero también sobre aquellos jóvenes que fueron autores de las movilizaciones masivas en contra de las armas. ${ }^{13}$ Moore considera que el verdadero cambio se encuentra en esas generaciones: están a favor de la diversidad sexual y el aborto, se han comprometido con el cambio climático, la regulación de las armas, etc. En suma, Moore intenta mostrar que el sistema no tiene salvación, sin dejar de señalar en quién ubica la esperanza de cambio.

Fiel a su estilo audiovisual, la voz en primera persona de Michael Moore no sólo guía nuestra comprensión de los acontecimientos, sino que él mismo es uno de los personajes principales. La autorreferencialidad es tal que incluye en la edición un fragmento de un noticiero televisivo que menciona su correcta predicción del resultado electoral, expone las características de los encuentros fortuitos que tuvo con Trump y miembros de su familia años atrás, además de vincular los equívocos del presidente con problemáticas específicas que enfrenta su comunidad -Flint, Michigan-. Desde esa postura personal rechaza y desaprueba al presidente, pero sustenta su posición con información (Nichols, 2013) y cadenas de valores (Dittus, 2012); por ejemplo, no es correcto desear sexualmente a tu hija, discriminar, asumir a las mujeres como objetos sexuales, desestimar el cambio climático, etcétera.

En los términos de las modalidades planteadas por Nichols (2013), este documental conjuga el modo expositivo con el modo participativo. ${ }^{14}$ Con base en el primero, congrega momentos del mundo histórico -Estados Unidos bajo la presidencia de Donald Trump- y nos informa sobre ellos. La robusta cantidad de información que se nos presenta - datos, cifras, declaraciones, testimonios, material de archivo- apunta a construir una percepción de seriedad y credibilidad. Funciona como evidencia que legitima el punto de vista de Michael Moore y le permite hacer juicios acerca de los actores sociales que conforman el entorno. El modo participativo tiene

13 En un sólo día se realizaron más de 700 manifestaciones en ciudades de todo Estados Unidos, la mayoría de ellas multitudinarias.

14 Las modalidades - o voces- rara vez se encuentran de manera homogénea. Lo común es que un mismo documental utilice más de una estrategia narrativa (Nichols, 2013; Plantinga, 2014). 
un peso menor; sin embargo, también está presente. Para mostrar las inquietudes y preocupaciones durante este periodo presidencial, aparece a cuadro realizando entrevistas o teniendo conversaciones con un conjunto amplio y diverso de sujetos sociales - desde un bombero hasta Bernie Sanders-. Pero también interpela a desprevenidos simpatizantes de Trump situándose en la entrada de la Trump Tower.

El papel de Michael Moore como miembro activo de la política estadounidense no concluyó con el estreno de sus documentales. Su postura ha permanecido dinámica. A través de su página oficial ${ }^{15}$ ha hecho explícitas sus posturas acerca de la política estadounidense y ha dado a conocer sus propuestas para enfrentar al régimen trumpista. En ella se puede leer una carta pública dirigida a Ivanka Trump - "Your Dad's Not Well"-. A nombre de la nación y el mundo le pide su intervención para sacar a su padre de la política, argumentando que está clínicamente loco y que necesita ayuda profesional.

En otra carta - "Trump is Not The Only Grabber Who Must Go"se dirige al pueblo estadounidense para hacerle notar que todo lo que el presidente encarna es el resultado de la cultura republicana. En tanto, está publicada la iniciativa Need to Impeach, una petición avalada ya por más de ocho millones de estadounidenses, que solicitan la destitución del presidente. Moore Invita a sus seguidores a firmarla y difundirla. Acciones similares emprende desde su cuenta de Facebook y Twitter. Tampoco ha dejado de lado ejercicios como el de Michael Moore in Trumpland (2016). Como parte de las acciones que propuso para enfrentar al gobierno de Donald Trump, ${ }^{16}$ montó nuevamente un número, esta vez llamado The Terms Of My Surrender. Estas actividades son relevantes, porque desde la perspectiva de Nichols (2013) la modalidad participativa también incluye al público del documental como parte de la interacción y afirma que el involucramiento que se da a través de distintas plataformas es también parte de esta dinámica.

15 www.michaelmoore.com

16 1) Acciones ciudadanas masivas; 2) postular a candidatos que puedan ganar; 3) coartar a Trump con órdenes judiciales; 4) formar un ejército de satiristas para luchar con humor y difundir los riesgos que este hombre encarna al frente de la Casa Blanca. 


\section{Ken Burns y su crítica a Donald Trump}

\section{The Central Park Five (2012)}

Los estrenos del trabajo de Ken Burns no tienen una vinculación necesaria con lo que sucede en la política estadounidense. No es casualidad que en 2012 -más de veinte años después de que se incriminara a cinco jóvenes afrodescendientes por un crimen cometido en Central Park- se estrenara su documental sobre estos acontecimientos. The Central Park Five (2012) reconstruye la historia desde la mirada de estos actores sociales. Con música de época, testimonios de los afectados y sus familiares, fotografías, datos hemerográficos, archivos de noticieros televisivos, archivos fílmicos de los juicios y los interrogatorios en las oficinas policiacas, muestra la falla del sistema de justicia estadounidense.

Cada pieza del rompecabezas revela que nadie hizo su trabajo -policías, detectives, fiscales- y pone en evidencia que todos mintieron. Deja ver que estos jóvenes quedaron atrapados en un sistema donde prevalece la discriminación y el odio hacia la comunidad afrodescendiente. De ahí que Burns dedique una buena parte del documental a mostrar que fueron forzados a declarar acerca de un suceso que desconocían y en el cual no estuvieron presentes. Sin evidencia de ADN que probara su participación, tal declaración fue lo único que se usó para determinarlos culpables.

Es en ese contexto donde un temprano Donald Trump decidió intervenir. Pagó miles de dólares para que los principales periódicos publicaran en una página completa una declaración donde pidió la pena de muerte para los adolescentes, e hizo declaraciones en televisión que incitaron aún más el rechazo hacia estos jóvenes. El documental destaca una de ellas: "Puedo asegurarles que siento odio hacia las personas que se llevaron a esta chica y la violaron. Se los aseguro". ${ }^{17}$ Según los datos que se presentan, la intervención de Trump provocó que $76 \%$ de los neoyorquinos se mostraran a favor de aplicar la pena de muerte a criminales, sin importar si eran menores de edad.

Cuando el documental se estrenó, los jóvenes ya habían sido exonerados. Para ello fue fundamental la confesión del verdadero perpetrador, cuyo ADN sí coincidía con el encontrado en la escena del crimen. Sin embargo, Trump declaró sobre el documental: "El documental The Central Park Five

17 Pero hubo otras del mismo Donald Trump en relación con el caso que nos ocupa: "Por supuesto que odio a esta gente. Y vamos a odiar todos a esta gente porque tal vez el odio es lo que necesitamos para conseguir que se haga algo”, “...es más que odio y quiero que la sociedad los odie" (Now This, 2019). 
fue una pieza de basura que no explica el horror del crimen de esos jóvenes en el parque" (Now This, 2019); es decir, con todo y la evidencia que había del equívoco, el ahora presidente de Estados Unidos no se retractó.

Tampoco lo hizo en 2016 ni en 2017, cuando los reporteros lo interrogaron sobre el tema. En el primer momento Burns usó este caso para hacer notar el racismo de Trump. En la segunda circunstancia, junto con Now This, hizo un video difundiendo las declaraciones del presidente respecto a los acontecimientos. El objetivo era mostrar el peligro que entrañaba para la población. En esos años, Burns ha dado un buen número de entrevistas donde ha declarado que para él es fundamental combatir el racismo que subyace en la cultura estadounidense (Now This, 2019; Collins, 2016; Ferner, 2016). De ahí la importancia de que la gente conozca la historia de Central Park y el comportamiento del presidente.

The Central Park Five (2012) funciona mediante un énfasis que el teórico Bill Nichols (2013) ubica en los documentales de retrato personal. Se trata de una estrategia donde los personajes principales hablan de sí mismos, tal como sucede con los cinco jóvenes acusados, porque tiene como objetivo mostrar al público que el conocimiento emana de personas que experimentaron los acontecimientos de manera directa. Es así que los relatos están construidos desde la experiencia individual, remiten a sentimientos y momentos del ámbito privado. Se ponen de relieve las cualidades de los actores sociales y los desafíos que han debido enfrentar. Por ello no hace falta que reflexionen sobre la problemática -el racismo contra la comunidad afrodescendiente-, basta con que cuenten el modo como trastocó sus vidas de manera irreversible. La intensidad del relato genera empatía con el público.

Con menor peso también están presentes rasgos de las modalidades expositiva y participativa (Nichols, 2013). La búsqueda de una cabal representación de los actores sociales afectados por el racismo, así como la intención de informar y conmover al público, son atributos de la primera. El cuidado que el documental pone en la dignidad de los sujetos y el puente que construye entre pasado y presente son características de la segunda.

\section{Conclusiones}

Michael Moore y Ken Burns tienen posturas distintas, tanto en la manera de hacer cine como en la adscripción política. Muy probablemente Burns nunca hubiera votado por Bernie Sanders. En 2016 señaló que Sanders y Trump fragmentaban al pueblo estadounidense en vez de unirlo (CNN Business, 2016). A diferencia de Moore que combina su profesión con su postura 
política, Burns ha procedido en este ámbito de forma cauta y sobria; lo cual muestra que hay distintas maneras e intensidades de actuar mediáticamente en el terreno de la producción documental. La postura política del primero es explícita y accesible. No pasa lo mismo con el segundo, pues se requiere un trabajo más acucioso de búsqueda y deducción. Moore ubica el futuro en las minorías y en los jóvenes, mientras que Burns en una reconstrucción incluyente de la historia estadounidense. No obstante, en la era Trump estos dispares personajes coinciden en el mismo lado de la trinchera. Comparten el rechazo al actual presidente de Estados Unidos, la lucha para erradicar y denunciar el racismo en contra de las minorías, así como también la sensación de que la nación y su gente se encuentran en peligro.

Con base en la legitimidad que ha alcanzado a través de sus múltiples documentales y en la amplia proyección que estos han tenido, Michael Moore se ha convertido en un personaje activo de la política de su país (Oberacker, 2009). A través de distintas plataformas no sólo se mantiene en contacto con el público, sino que da a conocer sus opiniones, apuntalando el diálogo sobre los temas que están en juego en una gama amplia y diversa de sectores. Por su trayectoria, sus premisas se discuten tanto en las élites de curadores de festivales, como entre el público que visita el cine buscando únicamente un par de horas de entretenimiento. Y aunque haya gente que difiera de sus posturas, lo relevante no está ahí. Lo que importa, diría Kahana (2008), es que éstas mantienen abierto y vigente el debate en torno a la política estadounidense. Hoy en día respecto a si Trump debe seguir como presidente o no.

En este sentido, resulta cuestionable que Ricciardelli (2014: 106-124) califique como deshonesta la participación política de Michael Moore. Le reclama que su verdadera búsqueda sea avanzar en su agenda política y en sus reclamos sociales, facilitando la identificación del público con sus intereses. Da la impresión de que para Ricciardelli (2014) un documentalista pierde legitimidad cuando sus motivaciones no se limitan a hacer cine y se mezclan con un posicionamiento político. Al recordar la trayectoria de nueve décadas del documental político en Estados Unidos y sus acciones para transgredir las versiones oficiales en momentos de tensión política, se vuelve evidente que la autora elabora un análisis más bien descontextualizado, tanto de la historia del documental estadounidense como de las motivaciones del trabajo de Moore; es decir, no logra vincular la tradición activista del documental y su apuesta por incidir en la política con las motivaciones de Moore. Si se toma en cuenta que él se volvió documentalista a partir de la necesidad de denunciar la crisis económica y laboral en la cual se vio sumida la comunidad donde creció, entonces es evidente que quería participar en lo que estaba pasando. 
Lo mismo ocurre con el resto de sus documentales. Moore espera que el público se vuelva empático con su punto de vista y se involucre.

En el caso de Burns, lo que interesa notar es que originalmente su documental no se hizo para cuestionar a Donald Trump. El objetivo era mostrar el horror que vivieron estos adolescentes sólo por ser afrodescendientes y llevarnos a concluir que en Estados Unidos este tipo de injusticias son cotidianas. Sin embargo, a pesar de la postura que había caracterizado al director -en ocasiones catalogada como conservadora (Nichols, 2013)-, decidió utilizar el documental para hacer frente a un contexto que encuentra amenazante para la población entera.

El eco logrado por The Central Park Five (2012) muestra la capacidad para traer al presente un asunto del pasado, para poner en evidencia el criterio racial del empresario en el presente y sumar nuevos públicos a la discusión. Ayuda a mostrar que Trump tiene la misma postura de hace tres décadas y que esa ausencia de autocrítica es un riesgo para la población. Al seguir a Kahana (2008), este tipo de materiales construyen una suerte de pedagogía social, porque informan e instruyen a la gente sobre un acontecimiento.

La accesibilidad del discurso audiovisual permite que funcione en ámbitos distintos, construyendo un puente entre el conocimiento académico y el sentido común; pero sobre todo debilitando la versión hegemónica y complejizando el imaginario social acerca de la discriminación racial en Estados Unidos. Cuando este diálogo no sólo se limita al realizador y al público, sino que se lleva a la arena política, es común que se sumen múltiples actores, como la reciente serie de Netflix: When They See Us (2019), entre otros programas de televisión que trataron el tema.

Por ello llama la atención que el análisis de Ricciardelli (2014: 79-105) caracterice el trabajo de Ken Burns a partir de una sola y nada reciente serie - The Civil War (1990)-, al señalar que este director tiende a simplificar la experiencia estadounidense y a homogeneizar las diferencias culturales. Si bien es cierto que en su momento la citada serie documental fue motivo de cuestionamientos, es fundamental notar que los realizadores y sus enfoques están lejos de ser anacrónicos. The Central Park Five (2012) muestra, a partir de testimonios de los afectados, cuáles son los costos y riesgos de ser distinto, de no ser blanco. La historia logra retratar aquello que se oculta en la cotidianidad de la sociedad estadounidense: el profundo racismo y sus consecuencias. Muestra que Estados Unidos está muy lejos de ser una nación donde las diferencias físicas y culturales carecen de importancia. De ahí que caracterizar a un documentalista a partir de una sola obra resulte arriesgado. 
La revisión de los materiales, las trayectorias y particularidades de sus autores reflejan la manera en que el documental es usado como herramienta para construir tanto el pasado como el futuro; pero sobre todo para subvertir el presente, tal como muestran los casos analizados. Fieles a la genealogía que los antecede, nos enseñan que el documental en Estados Unidos sigue teniendo un papel activo en la configuración de su historia y su entorno; se producen como respuesta y opción a un cerco informativo. Reflejan el valor que tienen cuando se abren debates en la sociedad, porque proveen información al público permitiéndole tomar una postura.

Asimismo, fue posible conocer algunas de las estrategias de resistencia y comunicación de un sector de la sociedad estadounidense vinculado con la producción audiovisual, la televisión pública, las universidades, escuelas y festivales de cine. Esto permitió distinguir algunas de las voces disidentes de la región -y sus matices- en relación con Donald Trump. También se puso de relieve que este presidente ha sacudido de tal modo la política estadounidense, que ha propiciado que sectores distantes coincidan y que sus respectivas posturas se radicalicen.

\section{Referencias}

Barnouw, Erik (2011), El documental. Historia y estilo, España: Gedisa.

Benson, Thomas y Snee, Brian [eds.] (2015), Michael Moore and the Rhetoric of Documentary, Estados Unidos: Southern Illinois University Press.

Bleum, William (1971), Documentary in American Television, Estados Unidos: Hastings House.

Brent Toplin, Robert (1996), Ken Burn's The Civil War: Historians Respond, Inglaterra; Oxford-University Press.

CNN Business (2016), "Ken Burns: Trump divides us Sanders too" [video online]. Disponible en: https://www.youtube.com/watch?v=5M0DyobP1w [28 de enero de 2010].

Collins, Eliza (2016), "Ken Burns On Trump Speech", en USA Today. Disponible en: https://www.usatoday.com/story/news/politics/2016/06/17ken-burns-trumpstandford/86045676 [24 de enero de 2020].

Dittus, Rubén (2012), "Imágenes y poder: El dispositivo en el documental político", en Revista de Investigaciones Politicas y Sociológicas, vol. 11, núm. 2, España: Universidad de Santiago de Compostela.

Dixon, John y Skidmore, Max [eds.] (2018), Donald J. Trump's Presidency. International Perspectives, Estados Unidos: Westphalia Press.

Edgerton, Gary (2001), Ken Burn's America, Estados Unidos: Palgrave.

Ferner, Matt (2016), "Ken Burns Blasts Trump For Insisting The Central Park 5 Are Guilty", en Huffpost. Disponible en: https://www.huffpost.com/entry/ken-burnstrump-central-park-five_n_57f7ebf9e4b0e655eab3f20b?guccounter $=1$ \&guce_refer rer=aHR0cHM6Ly93d3cuZ29vZ2xlLmNvbS8\&guce_referrer_sig=AQAAAFR-h- 
LR7qErmeX9n_hTg5ag28oaWMkcEyqso0IQKDOsP2njnN07egWSq4gHYuR-7Wo b4WveUwHAnvV5FFrodvdlsISFIrFo8arfG2uN2SWs9oEKqHqAp_G_3hU7y4ES6I6 mpq-BO1n8QbtHYvdP99FiWeiOMjVRCdbA5M7LwINJ [24 de enero de 2020].

Ferro, Marc (2008), El cine, una visión de la historia, España: Akal.

Ferro, Marc (1980), Cine e historia, España: Gustavo Gili.

Fleischmann, Aloys (2007), “The Rhetorical Function of Comedy in Michael Moore's Fahrenheit 9/11", en Mosaic: An Interdisciplinary Critical Journal, vol. 40, núm. 4, Canadá: University of Manitoba.

Geiger, Jeffrey (2011), Documentary in American Television, Escocia: Edinburgh University Press.

Giroux, Sylvain y Tremblay, Ginette (2011), Metodología de las ciencias humanas, México: Fondo de Cultura Económica.

Granados, Víctor Manuel (2006), “Moore y la forma de hacer y ver documentales”, en Sociológica, vol. 21, núm. 61, México: Universidad Autónoma Metropolitana.

Kahana, Joanthan (2008), Intelligence Work. The Politics of American Documentary, Estados Unidos: Columbia University Press.

Lerner, Gerda (1992), The Female Experience: An American Documentary, Estados Unidos: Oxford University Press.

Leuthold, Steve (2001), Rhetorical Dimensions of Native American Documentary, Estados Unidos: University Minnesota Press.

Lovely, Mary y Liang, Yang (2018), “Trump Tariffs Primarily Hit Multinational Supply Chains, Harm US Technology Competitiveness", en Policy Brief, Estados Unidos: Peterson Institute For International Economics.

MacDonald, Scott (2013), American Ethnographic Film and Personal Documentary, Estados Unidos: University of California Press.

Martínez-Zalce, Graciela (2018), "Los Simpson versus Trump”, en Núñez, Silvia [ed.], La presidencia de Donald Trump. Contingencia y conflicto, México: Centro de Investigaciones sobre América del Norte y Universidad Nacional Autónoma de México.

Martínez-Zalce, Graciela (2005), "Michael Moore and Trey Parker Two Interpretations of the U.S.-Canadian Border”, en Voices of Mexico, vol. 71, México: Centro de Investigaciones sobre América del Norte y Universidad Nacional Autónoma de México.

Moore, Michael (2013), Cuidado conmigo, España: Maxi Pocket.

Nichols, Bill (2013), Introducción al documental, México: Universidad Nacional Autónoma de México y Centro Universitario de Estudios Cinematográficos.

Nichols, Bill (1997), La representación de la realidad, España: Paidós.

Now This (2019), "Donald Trump's Horrific Response to the Central Park Five Case" [video on line]. Disponible en: https://youtube.com/watch?=Paf 8MPhSG08 [24 de enero de 2020].

Núñez, Silvia [ed.] (2018), La presidencia de Donald Trump. Contingencia y conflicto, México: Centro de Investigaciones sobre América del Norte, Universidad Nacional Autónoma de México

Oberacker, Jon Scott (2009), “The People and Me: Michael Moore and The Politics of Political Documentary”, en Open Access Dissertations, núm. 65, Estados Unidos: University of Massachusetts Amherst.

Plantinga, Carl (2014), Retórica y representación en el cine de no ficción, México: Centro Universitario de Estudios Cinematográficos, Universidad Nacional Autónoma de México. 
Ricciardelli, Lucía (2014), American Documentary. Filmmaking in the Digital Age. Depictions of Wars in Burns, Moore and Morris, Estados Unidos: Routledge.

Sierra, Francisco y Montero, David [eds.] (2015), Videoactivismo y movimientos sociales. Teoria y praxis de las multitudes contectadas, España: Gedisa.

Stern, Marlow (2017), “Ken Burns: Trump Lusts After His Own Daughter”, en Daily Beast. Disponible en: https://www.thedailybeast.com/ken-burns-trump-lusts-after-his-owndaighter? ref $=$ scroll [ 24 de enero de 2020].

Wolff, Michael (2018), Fire and Fury. Inside the Trump White House, Estados Unidos: Little Brown.

Wulfsohn, Joseph (2020), "Michael Moore warns Dems about Trump reelection”, en Fox News. Disponible en: https://www.foxnews.com/entertainment/michael-moorewarns-dems-about-a-trump-reelection-he-knows-exactly-what-hes-doing [ 23 de mayo de 2020].

Liliana Cordero Marines. Doctora en Antropología. Programa de Becas Posdoctorales de la Universidad Nacional Autónoma de México (UNAM), becaria del Centro de Investigaciones sobre América del Norte (CISAN), asesorada por la doctora Graciela Martínez-Zalce Sánchez. Línea de investigación: cine documental de denuncia política en América del Norte. Publicaciones recientes: Cordero Marines, Liliana (2019), "Documental político en Norteamérica: una herramienta de contrainformación y configuración de las identidades políticas", en Norteamérica, núm. 1, México: CISAN-UNAM; Cordero Marines, Liliana (2018), "A Documentary Shines a New Line”, en Voices of Mexico, núm. 106, México: CISAN-UNAM; Cordero Marines, Liliana (2017), "Trayectorias de la cultura visual tijuanense: Un estudio antropológico de la producción y exhibición audiovisual durante el período 1990-2009”, en Gómez, Lizbeth, Tijuana: De la panorámica al close-up, México: Instituto de Cultura de Baja California. 